\title{
HIV infection mimiking amyotrophic lateral sclerosis - a three-year follow-up
}

\author{
Vlad-Ioan Suciu', Corina-Iuliana Suciu², Cosmin Catalin Mutu2,3 \\ ${ }^{1}$ Private practice - Neurology, Sibiu, Romania \\ ${ }^{2}$ Academic Emergency Hospital, Sibiu, Romania \\ 3"Lucian Blaga" University, Sibiu, Romania
}

\begin{abstract}
In this paper we present the clinical course during 3 years of follow-up of a patient who was admitted in our clinic being formerly diagnosed with sporadic amyotrophic lateral sclerosis (ALS). After he was diagnosed in 2016 with ALS, he was treated with Riluzole for 6 months, but his symptoms aggravated in this period of time. During the first admission in our department, he presented a flail-arm syndrome with bilateral scapula alata, facio-scapulo-humeral wasting, fasciculations, abolished reflexes in the upper limbs, generalized pruritus, xeroderma and weight loss over $25 \mathrm{~kg}$. Extensive investigations revealed the HIV infection for which he was referred then to the nearest infectious diseases center for proper treatment. A follow-up spanning on 3 years, revealed increased muscle power and improved muscle bulk after HAART therapy.

In this paper we present the case report and a short to the point literature review of amyotrophic lateral sclerosis mimics in HIV infection.
\end{abstract}

Keywords: amyotrophic lateral sclerosis mimics, HIV infection, nervous system involvement in HIV infection, "flail-arm" syndrome, "man in the barrel" syndrome

\section{INTRODUCTION}

The neurologic manifestations in HIV infected patients appear secondary to the antiretroviral agents, opportunistic infections, neoplasms or primary to direct lesions determined by the human immunodeficiency virus (1-3).

HIV infection determines lesions throughout the entire nervous system, central and/or peripheral. The virus infects glial supporting cells. Neuropathies secondary to HIV infection appear more frequent than myopathies (50\% versus $25 \%$ ). The prevalence of HIV-related neuropathy is 3,5/1.000 infected patients, while this syndrome can have its onset at any stage of the infection. Some authors believe that the HIV associated neuropathy can be diagnosed at more than one month after the infection in more than $72 \%$ of cases. The majority of patients displaying this constellation, present atrophy and weakness mostly in the upper limbs. The clinical evolution is relatively quick, but the
HAART treatment appears to stabilize the symptoms (1-4).

\section{CASE REPORT}

We present the case of a 64-year-old retired man, who was admitted in our clinic being formerly diagnosed with sporadic amyotrophic lateral sclerosis. His symptoms had aggravated in the first 6 months of Riluzole treatment, after the diagnosis. Until 2014, our patient informed us that he had been a constant blood donor, being investigated for infections (including HIV) thoroughly every time. He had no knowledge of suffering from any illness.

During the first admission in our department (2016), he accused a rapid progressive wasting of the muscles of the scapulo-humeral limb girdle, generalized pruritus and weight loss (over $25 \mathrm{~kg}$ in 6 months).

The clinical exam revealed shoulder girdle muscle atrophy, bilateral scapula alata, Aran-Duchenne 
muscle atrophy of the hands, negative Gower's sign, fasciculations mainly in the upper limbs, decreased strength in all limbs, more pronounced in the proximal muscles of the upper limbs, dificulty in raising the arms even for eating, no myotonia, absent reflexes in the upper limbs, no pyramidal pathological signs, normal cranial nerves function and no sensory signs.

On first sight, it seemed that the clinical presentation suggested a rare form of ALS known as the "flail-arm" syndrome or the "man in the barrel" syndrome (see figure 1 and 2).

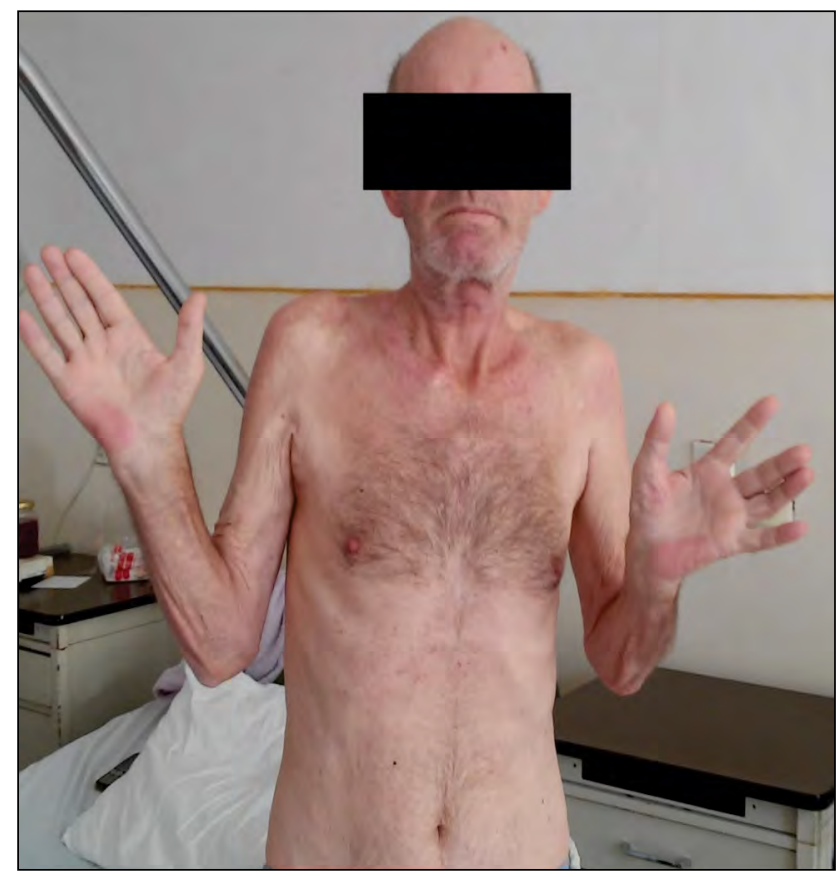

FIGURE 1. Shoulder girdle muscle wasting

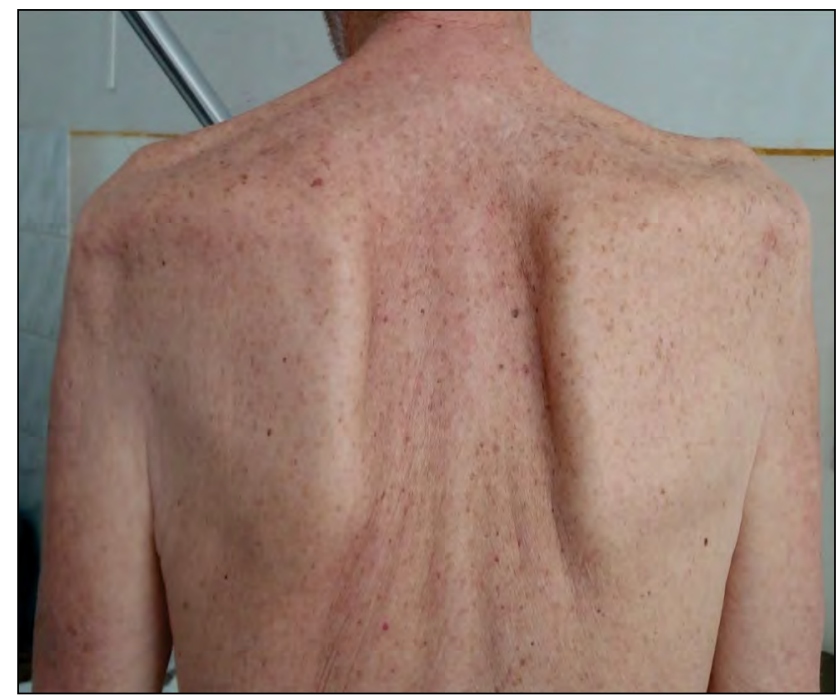

FIGURE 2. Bilateral scapula alata

The usual blood tests showed a slight leucopenia (white blood cell count of $3,600 / \mathrm{mm}^{3}$ ) with lymphopenia $\left(740 / \mathrm{mm}^{3}\right)$, anemia (Hb $10 \mathrm{~g} / \mathrm{dl}$ ), thrombocytopenia (PLT 100,000/ $\mathrm{mm}^{3}$ ), inflammatory reaction (ESR $47 \mathrm{~mm} / \mathrm{h}$, but negative CRP), and hypothyroidism $\left(\mathrm{T}_{4} 0.769 \mathrm{ng} / \mathrm{dl}\right.$, normal range 0.89-1.76). Muscle enzymes, serum protein electrophoresis, liver and renal function tests, B12 vitamin, folic acid, electrolytes and blood glucose were all normal.

The spyrometric evaluation revealed a mild restrictive respiratory insufficiency, but the oxygen saturation levels were normal.

The lumbar puncture was performed in the second day of the admission, and it revealed a slightly increased albumin $(0.47 \mathrm{~g} / \mathrm{L})$ with no cells. The nerve conduction tests showed decreased amplitudes at the stimulation of the motor nerves in the upper limbs, predominantly on the right side, consistent with an axonopathy of the median, ulnar, axillary and radial nerves. The lower limbs showed no motor abnormality and the sensory nerve conduction studies were also normal in all limbs.

The spinal MRI showed multiple intervertebral disc herniations at $\mathrm{C} 3$ through $\mathrm{C} 6, \mathrm{~T} 6$ with bilateral radicular compressions but with no compressive myelopathy signs.

The cranial computed tomography excluded a pathological process at this level.

More extensive blood work in order to detect anomalies that could explain the abnormal blood count revealed positive anti-HIV antibodies confirmed later by Western blot techniques. The teraphy with Riluzole was immediately stopped and we referred the patient to the regional infectious diseases hospital for further investigations and treatment. The CD4 cell count was $36 / \mathrm{mm}^{3}$. A CMV infection was associated, but no chorio-retinitis was found during the ophthalmologic examination. He received HAART treatment with Darunavir, Tenofovir, Emtricitabine and Ritonavir.

At the follow-up after one year (2017), the patient had gained weight and his muscle strength in the upper limbs had slightly increased, thus increasing the quality of life and allowing him to selffeed. No further progression was detected at the clinical exam, however, the muscle atrophy remained constant (see figure 3 ).

At this point, it was clear that the halted progression during one year with antiretroviral therapy was the proof of HIV related neuropathy rather 


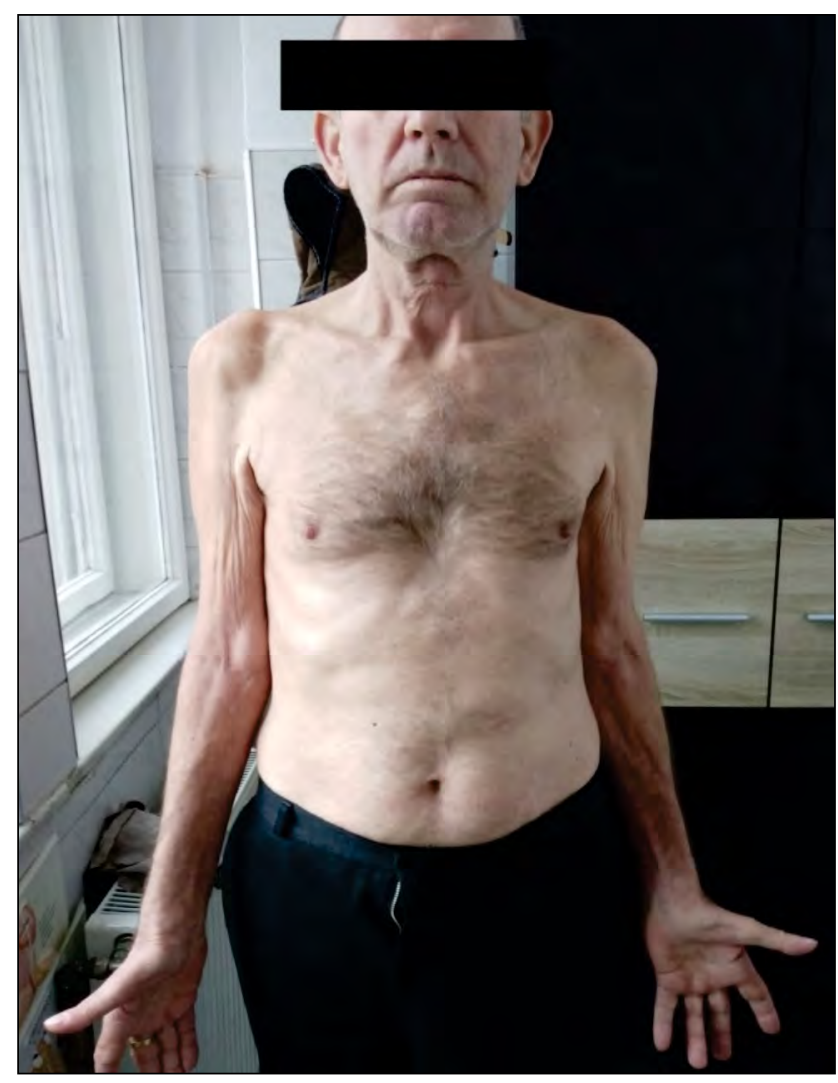

FIGURE 3. Clinical follow-up at one year

than the formerly believed rare form of ALS. The patient was also monitored periodically at the infectious diseases center.

After three years of antiviral treatment, the clinical and neurologic status was stable. No other anomalies, and no signs of progression of the motor neuron disease were detected.

\section{DISCUSSION}

According to the medical literature, the first case of motor neuron disease associated to HIV infected patients was first presented in 1985 and afterwards, few case reports were published with this association. Anand et al. observed that HIV-associated ALS (HALS) tends to occur in younger patients, progresses faster than ALS, but improves after antiviral therapy (5).

Henning et al. reported in 2008 that only one case was reported before his published paper, describing HALS. Henning and Hewlett described a HALS case in a patient formerly diagnosed with HIV infection and presenting T2 signal change in the anterior grey matter of the cervical cord by MRI (6).

In 2013, Lee and colleagues reported a case of a 32 year old woman presenting a brachial amyo- trophic diparesis with anti-Hu antibodies, discovering this way another cause of the bilateral brachial paresis ("flail-arm syndrome" or "man in the barrel" syndrome) (7).

Another paper published by Yang and colleagues in 2015 revealed that the flail-arm syndrome could be indeed a different entity from the classic amyotrophic lateral sclerosis and that the flail-arm syndrome is characterized by a severe and symmetric flaccid motor deficit with muscle atrophy in the proximal parts of the upper limbs, but with few or no signs in the lower limbs or bulbar muscles. The flail-arm syndrome seems to have a male predominance and a slower evolution compared to the classic amyotrophic lateral sclerosis (8).

More recently, authors believe that the flail-arm syndrome is an atypical form of the amyotrophic lateral sclerosis, and that the nerve conduction studies cannot set apart the two entities. However, the "owl's sign" characterized by T2 hyperintensities (MRI) in the anterior horn cells of the spinal cord could be more specific for the flail-arm syndrome. Fasciculations seem to be more rare in flailarm syndrome than in amyotrophic lateral sclerosis $(9,10)$.

We have found three arguments which demonstrate that the first clinical impression of an ALS was wrong, despite the rapid progressive evolution of the condition.

First, the weight loss was disproportionate fast-evolving, to the muscle wasting, which remained constant after three years of antiretroviral therapy. Secondly, the El Escorial criteria for the diagnosis of ALS were not accomplished for a definite diagnosis, because pyramidal tract signs were and remained absent throughout the clinical evolution. The abnormal blood count which revealed a pancythopenia was the third argument to suspect an alternate diagnosis to ALS. Indeed, the cervico-dorsal disc herniations could explain some of the upper limbs motor deficits, but it did not fit into the whole clinical picture of weight loss, blood test anomalies, xeroderma, and so on.

The Romanian Society of Neurology guidelines (based on the European Academy of Neurology), also recommend further investigations in carefully selected patients. Taking into account our findings we excluded autoimmune and demyelinating lesions. The patient had no history of a tick byte, but 
the ELISA HIV screening test was performed twice, and then confirmed by the Western blot technique. The HIV infection fitted best in the clinical context. For a higher diagnostic yield, repeated examinations were performed in three years of follow-up (4).
We believe that the flail-arm syndrome, also known as the "Man in the barrel" syndrome, or the bilateral brachial paresis could be considered a distinct medical condition. The bibrachial paresis can be caused by various heterogenic entities both central and peripheral nervous system lesions.

TABLE 1. The Romanian Society of Neurology recommendations for ancillary investigations in motor neuron disease (4) *

\begin{tabular}{|c|c|c|c|c|}
\hline $\begin{array}{l}\text { Ancillary } \\
\text { investigations }\end{array}$ & Test & Evidence class & $\begin{array}{c}\text { Mandatory } \\
\text { investigations }\end{array}$ & $\begin{array}{l}\text { Investigations } \\
\text { recommended in } \\
\text { selected cases }\end{array}$ \\
\hline \multirow{19}{*}{ Blood tests } & Erithrocyte sedimentation rate & IV & $x$ & \\
\hline & C-reactive proteine & IV & $x$ & \\
\hline & ASAT, ALAT, LDH & IV & $\mathrm{x}$ & \\
\hline & TSH, fT3, fT4 & IV & $x$ & \\
\hline & B12 vitamin, folate & IV & $\mathrm{x}$ & \\
\hline & Serum protein electrophoresis & IV & $x$ & \\
\hline & Serum imunoelectrophoresis & IV & $x$ & \\
\hline & Creatinekinase & IV & $x$ & \\
\hline & Creatinin & IV & $x$ & \\
\hline & $\mathrm{Na}, \mathrm{K}, \mathrm{Cl}, \mathrm{Ca}, \mathrm{PO} 4$ & IV & $x$ & \\
\hline & Blood glucose & IV & $x$ & $x$ \\
\hline & Angiotensin converting enzyme & IV & & $x$ \\
\hline & Lactate & IV & & $x$ \\
\hline & Hexoaminidase A, B & IV & & $\mathrm{x}$ \\
\hline & Anti-GM-1 antibodies & IV & & $\mathrm{x}$ \\
\hline & Anti-Hu, anti-MAG antibodies & IV & & $x$ \\
\hline & $\begin{array}{l}\text { Rheumatoid factor, ANA, anti-DNA } \\
\text { antibodies }\end{array}$ & IV & & $x$ \\
\hline & $\begin{array}{l}\text { Anti-Ach receptor, anti-MUSK } \\
\text { antibodies }\end{array}$ & IV & & $x$ \\
\hline & Anti-Borrelia, anti-HIV antibodies & IV & & $x$ \\
\hline \multirow{7}{*}{$\begin{array}{l}\text { Cerebrospinal } \\
\text { fluid }\end{array}$} & Cell count & IV & & $x$ \\
\hline & Citology & IV & & $\mathrm{x}$ \\
\hline & CSF protein & IV & & $\mathrm{x}$ \\
\hline & CSF glucose and lactate & IV & & $\mathrm{x}$ \\
\hline & Protein electrophoresis, IgG & IV & & $x$ \\
\hline & Borrelia and viral infections markers & & & \\
\hline & Anti-gangliosidic antibodies & IV & & $x$ \\
\hline \multirow{4}{*}{ Urine } & Cadmium & IV & & $x$ \\
\hline & $\mathrm{Pb} / 24$ hours & IV & & $\mathrm{x}$ \\
\hline & $\mathrm{Hg}$ & IV & & $\mathrm{x}$ \\
\hline & $\mathrm{Mn}$ & IV & & $\mathrm{x}$ \\
\hline \multirow{3}{*}{ Electrophysiology } & Electroneurography & III & $\mathrm{x}$ & $\mathrm{x}$ \\
\hline & Nerve conduction studies & III & $\mathrm{x}$ & \\
\hline & Motor evoked potentials & IV & & $\mathrm{x}$ \\
\hline \multirow{3}{*}{ Radiology } & $\begin{array}{l}\text { Cerebral, cervical, thoracic, lumbar } \\
\text { MRI, CT-scans }\end{array}$ & IV & $x$ & \\
\hline & Chest radiograph & IV & $\mathrm{x}$ & \\
\hline & Mammography & IV & & $x$ \\
\hline \multirow{4}{*}{ Biopsy } & Muscle & III & & $\mathrm{X}$ \\
\hline & Nervous tissue & IV & & $x$ \\
\hline & Spine & IV & & $x$ \\
\hline & Lymphatic ganglia & IV & & $x$ \\
\hline
\end{tabular}

*Table translated and adapted in English from the Romanian Society of Neurology guidelines (4) by the authors of this paper 
The causes of the bibrachial paresis with amyotrophy are: HIV associated ALS-like syndrome (HALS), paraneoplastic neuropathies with anti-Hu antibodies, Guillain-Barré spectrum disorders, amyloid neuropathies, paraproteinemic neuropathies, toxic and metabolic neuropathies and cervical cord lesions (1-10).

A hypoxic-ischemic encephalopathy in which the ischemia predominates, can cause a bilateral watershed infarct between the anterior and middle cerebral arteries, thereby generating a bibrachial paresis without amyotrophy (3).

\section{CONCLUSIONS}

We strongly believe that this particular case reflects the importance of respecting the clinical guidelines in all clinical circumstances even in the almost certainty of a diagnosis.

The guidelines are elaborated by experts with strong proof from several clinical studies based on the principles of the evidence-based medicine. These guidelines can assure a quicker and more reliable diagnosis with a better patient care. Continuous efforts should be made to facilitate the usage and implementation of up-to-date guidelines in the ever-widening field of neurology.

Cases reflecting a potentially severe disease should be thoroughly reinvestigated and interpreted in the clinical context. Team-work among medical experts is also imperative in such complex cases.

Conflict of interest: none declared Financial support: none declared

\section{REFERENCES}

1. Nalini A, Desai A, Mahato SK. Flail arm-syndrome associated with HIV-1 infection. Ann Indian Acad Neurol 2009; 12(2): 127-30.

2. Alfahad $T$, Nath $A$. Retroviruses and amyotrophic lateral sclerosis. Antiviral Res 2013; 99(2): 180-7.

3. Ropper AH, Samuels MA, Klein JP. Adams and Victor's Principles of Neurology Tenth Edition. McGraw-Hill: China; 2014.

4. Băjenaru O. Ghiduri de diagnostic şitratamentînneurologie. Ediţia a doua. Amaltea: Bucureşti; 2010.

5. Anand KS, Wadhwa A, Garg J, Mahajan RK. Amyotrophic Lateral Sclerosis-Like Presentation in a HIV-Positive Patient. Journal of the International Association of Providers of AIDS Care. 2014; 13(6):515-18.

6. Henning F, Hewlett RH. Brachial amyotrophic diplegia associated with HIV infection. Journal of Neurology Neurosurgery and Psychiatry. 2008; 79(12):1392-94.

7. Lee Jl, Macht S, Albrecht P, Hartung HP, Goebels N. Brachial amyotrophic diparesis associated with anti-Hu positive anterior horn cell disease and autonomic disorder. Journal of Neurology. 2013; 260(1):301-2.

8. Yang H, Liu M, Li X, Cui B, Fang J, Cui L. Neurophysiological Differences between Flai Arm Syndrome and Amyotrophic Lateral Sclerosis. PLoS ONE. 2015;10(6): e0127601.

9. Kim JY, Park YK, Yoon B, Lee KO, Kim YD, Na SJ. Flail arm syndrome with several issues related to the diagnostic process. Annals of Clinical Neurophysiology. 2017;19:68-70.

10. Yoon BN, Choi SH, Rha JH, Kang SY, Lee KW, Sung JJ. Comparison between Flail Arm Syndrome and Upper Limb Onset Amyotrophic Lateral Sclerosis: Clinical Features and Electromyographic Findings. EXP Neurobiol. 2014;23(3):253-7. 